\title{
RESPONS PERTUMBUHAN TANAMAN CABAI RAWIT (Capsicum frutescens L.) TERHADAP PEMBERIAN JAMUR Trichoderma sp.
}

\author{
Ema Oktapia ${ }^{1 *}$ \\ ${ }^{1}$ PT. Dizamatra Powerindo \\ Tambang Batu Bara Sumatera Selatan \\ *e-mail:emaoktapia9895@gmail.com
}

\begin{abstract}
A research entitled Responses to the Growth of Chili Rawit (Capsicum frutescens L.) to Trichoderma sp Mushroom, March to June 2017 in Muara Siban Village, Lahat Regency, South Sumatra. This study aims to determine the Responses of Rawit Chillies Growth Against Giving Mushroom Trichoderma sp. The method used was Completely Randomized Design (RAL) with 6 treatments and 4 replications with the treatment details of P0 (without Trichoderma sp), P1 (25 g Trichoderma $\mathrm{sp} / \mathrm{kg}$ soil pellet), P2 (50 g of Trichoderma $\mathrm{sp} / \mathrm{kg}$ soil pellets ), P3 (75 g of Trichoderma $\mathrm{sp} / \mathrm{kg}$ soil pellets ),P4 (100 g of Trichoderma $\mathrm{sp} / \mathrm{kg}$ soil pellets) pellet, P5 (125 g of Trichoderma $\mathrm{sp} / \mathrm{kg}$ soil pellets), was analyzed by Analysis of Scales Variety (ANSIRA) at $5 \%$. The parameters observed in this study were plant height, stem diameter and number of leaves. The results of the analysis of Sidik Ragam (ANSIRA) showed that Trichoderma sp had significant effect on plant height, stem diameter, and number of leaves. The best treatment was found in the treatment of $75 \mathrm{~g}$ of Trichoderma $\mathrm{sp} \mathrm{/} \mathrm{kg}$ soil pellets because it has the highest average value of each parameter ie the average height of plant $25.7 \mathrm{~cm}$, stem diameter $3.22 \mathrm{~mm}$, and the number of leaves 15 strands, while the lowest yield In the treatment without Trichoderma sp pellet sp with an average height of 15.3 $\mathrm{cm}$, stem diameter $2.07 \mathrm{~mm}$, and leaf number 8.75 strands.
\end{abstract}

Keywords: Trichoderma sp, Growth, Chilli Rawit (Capsicum frutescens L.).

\begin{abstract}
ABSTRAK
Telah dilaksanakan penelitian yang berjudul Respons Pertumbuhan Tanaman Cabai Rawit (Capsicum frutescens L.) Terhadap Pemberian Jamur Trichoderma sp, pada bulan Maret sampai dengan bulan Juni 2017 di Desa Muara Siban Kabupaten Lahat, Sumatera Selatan. Penelitian ini bertujuan untuk mengetahui respons pertumbuhan tanaman cabai rawit terhadap pemberian jamur Trichoderma sp. Metode penelitian ini menggunakan Rancangan Acak Lengkap dengan 6 perlakuan dan 4 ulangan yaitu P0 (tanpa pelet Trichoderma sp), P1 (25 g pelet Trichoderma sp/ kg tanah), P2 (50 g pelet Trichoderma sp/ kg tanah), P3 (75 g pelet Trichoderma sp/ kg tanah), P4 (100 g pelet Trichoderma sp/ kg tanah), P5 (125 g pelet Trichoderma sp/ kg tanah), dianalisis dengan ANSIRA pada taraf 5\%. Parameter yang diamati dalam penelitian ini adalah tinggi tanaman, diameter batang dan jumlah daun.Hasil Analisis Sidik Ragam. bahwa pemberian Trichoderma sp berpengaruh nyata terhadap tinggi tanaman, diameter batang, dan jumlah daun. Perlakuan terbaik terdapat pada perlakuan $75 \mathrm{~g}$ pelet Trichoderma sp/ kg tanah dengan rata-rata tinggi tanaman $25,7 \mathrm{~cm}$, diameter batang $3,22 \mathrm{~mm}$, dan jumlah daun 15 helai, sedangkan hasil terendah pada perlakuan tanpa g pelet Trichoderma sp dengan rata-rata tinggi tanaman $15,3 \mathrm{~cm}$, diameter batang $2,07 \mathrm{~mm}$, dan jumlah daun 8,75 helai.
\end{abstract}

Kata Kunci: Trichoderma sp, pertumbuhan, cabai rawit (Capsicum frutescens L.). 


\section{PENDAHULUAN}

Tanaman cabai rawit (Capsicum frutescens L.) merupakan salah satu komoditas tanaman yang mempunyai nilai pemasaran yang tinggi dari segi konsumsi dan ekonomi. Tanaman cabai rawit banyak dikonsumsi hampir di seluruh Indonesia sebagai bahan pangan rumah tangga maupun sebagai pangan industri, bahkan untuk ekspor ke negara lain. Tanaman ini dapat dibudidayakan di dataran tinggi maupun dataran rendah, pada lahan sawah maupun lahan tegalan (Sumarni et al., 2005).

Belum optimalnya produktifitas cabai rawit, diantaranya disebabkan oleh tingginya serangan hama dan penyakit yang secara ekonomis dapat menurunkan produktiiftas. Patogen tanaman menjadi masalah penting dalam budidaya tanaman cabai rawit. Beberapa penyakit penting pada cabai rawit diantaranya adalah penyakit layu fusarium yang disebabkan oleh Fusarium oxysporum, penyakit busuk buah cabai yang disebabkan oleh Colletotrichum sp, penyakit bercak daun yang disebabkan oleh Cercospora capsici, penyakit busuk cabang yang disebabkan oleh Phytophthora capsici (Syukur et al., 2009).

Salah satu alternatif upaya peningkatan kuantitas dan kualitas produk pertanian khususnya cabai dapat dilakukan dengan pemanfaatan agen hayati (biopestisida) yang ramah lingkungan dan berbasis sumber daya hayati sebagai pengganti pestisida sintetik. Salah satu jamur yang dapat digunakan sebagai biospestisida yang bersifat antagonis bagi patogen tanaman yaitu Trichoderma sp. Trichoderma sp diketahui mempunyai kemampuan antagonistik sebagai pengendali hayati yang potensial pada beberapa tanaman. Trichoderma sp memiliki beberapa keunggulan komperatif yang tinggi, bersifat mikroparasitik, mampu berkompetisi dalam memperoleh ruang, menghasilkan antibiotik dan enzim yang merugikan organisme patogen (Dina, 2003).

Trichoderma sp merupakan jamur penghuni tanah yang dapat diisolasi dari perakaran tanaman lapangan. Trichoderma sp merupakan jamur dari class Deuteromycetes yang memiliki daya kompetitif tinggi. Perkembangan aseksualnya yaitu dengan menghasilkan konidiospora yang bercabang-cabang. Hifa Trichoderma sp ini berbentuk pipih, bersekat dan bercabang-cabang membentuk anyaman yang disebut dengan miselium. Miseliumnya dapat tumbuh dengan cepat dan dapat memproduksi berjuta-juta spora. Jamur ini memiliki daya reproduksi tinggi, siklus hidup yang singkat dan memiliki spora yang bertahan lama di alam. Penggunaan Trichoderma sp merupakan alternatif dalam meningkatkan mikroba tanah yang akan mempercepat proses pengomposan, menjaga kesuburan tanah. Trichoderma $\mathrm{sp}$ disamping sebagai organisme pengurai juga berfungsi sebagai agen hayati dan stimulator pertumbuhan tanaman. Trichoderma $\mathrm{sp}$ memberikan pengaruh positif terhadap perakaran tanaman, pertumbuhan tanaman dan hasil produksi tanaman (Herlina, 2009).

Trichoderma sp diketahui terbukti mampu menghambat perkembangan patogen tanaman. Trichoderma sp merupakan jenis jamur yang dapat ditemukan di tanah hutan maupun tanah pertanian. Tran (2010) menyatakan bahwa Trichoderma sp memiliki peranan yang sangat penting untuk menekan pertumbuhan patogen jamur tanaman, khususnya jamur tular tanah. Trichoderma sp dalam kondisi in vitro mampu menekan pertumbuhan Fusarium sp yang diisolasi dari jaringan batang cabai. Presentase antagonis Trichoderma sp pada Fusarium sp secara in vitro sebesar 94,2\% (Mukarlina et al., 2010). 
Trichoderma sp memiliki fungsi seperti bersifat prepentiv terhadap penyakit, selain itu juga Trichoderma sp mempengaruhi mikroorganisme dalam tanah sehingga pemberian Trichoderma sp mempengaruhi struktur tanah, daya ikat tanah, daya ikat air dan meningkatkan ketersediaan unsur hara dan mengurangi ancaman kekeringan, memperbaiki aerasi tanah dan tata udara mikro tanah, akibatnya terlihat pada pertumbuhan tanaman yang lebih baik.

Perbanyakan Trichoderma sp dapat dilakukan pada media pelet. Pelet mengandung karbohidrat, protein dan kandungan nutrisi yang dibutuhkan Trichoderma sp dapat berkembang dengan baik. Biakan Trichoderma sp dalam aplikasi seperti pelet dapat diberikan ke areal pertanaman. Introduksi pelet Trichoderma sp 20 gram $/ 2 \mathrm{~kg}$ tanah mampu menekan perkembangan penyakit layu Fusarium dan meningkatkan tinggi tanaman dan berat basah pada tanaman tomat. Hasil penelitian Eddy dan Wahyu (2006), bahwa introduksi Trichoderma sp $50 \mathrm{gram} / 2 \mathrm{~kg}$ media tanam mampu menekan perkembangan penyakit layu fusarium dan mempertahankan pertumbuhan (tinggi tanaman dan jumlah daun) serta hasil (jumlah dan bobot buah) tanaman tomat. Berdasarkan uraian diatas, penulis ingin mengetahui bagaimana pengaruh pemberian jamur Trichoderma sp dalam meningkatkan pertumbuhan tanaman cabai rawit (Capsicum frutescens L.).

\section{BAHAN DAN METODE}

Alat yang digunakan dalam penelitian ini adalah penggaris, jangka sorong, timbangan, polibag ukuran $1 \mathrm{~kg}$, kertas label, ember. Bahan yang digunakan adalah: Jamur Trichoderma sp dalam sediaan media pelet, tanah humus, benih cabai rawit (Capsicum frutescens L.) dan air.
Penelitian ini merupakan penelitian eksperimen menggunakan metode Rancangan Acak Lengkap (RAL) yang terdiri dari 6 perlakuan pemberian Trichoderma sp dan 4 ulangan yaitu:

$\mathrm{P}_{0}=$ Kontrol/ Tanpa pelet Trichoderma $\mathrm{sp}$

$\mathrm{P}_{1}=25$ gram pelet Trichoderma $\mathrm{sp} / \mathrm{kg}$ tanah

$\mathrm{P}_{2}=50$ gram pelet Trichoderma $\mathrm{sp} / \mathrm{kg}$ tanah

$\mathrm{P}_{3}=75$ gram pelet Trichoderma $\mathrm{sp} / \mathrm{kg}$ tanah

$\mathrm{P}_{4}=100$ gram pelet Trichoderma $\mathrm{sp} / \mathrm{kg}$ tanah

$\mathrm{P}_{5}=125$ gram pelet Trichoderma $\mathrm{sp} / \mathrm{kg}$ tanah

Keterangan: 1 gram pelet mengandung 16,47 × 10 6 konidia Trichoderma sp.

(Sumber: Balai Proteksi Tanaman

Perkebunan Palembang, 2014)

\section{Cara Kerja}

\section{Pemilihan Benih Bibit Cabai Rawit (Capsicum frutescens $\mathrm{L}$.)}

Benih cabai rawit yang dipilih adalah benih yang baik dengan ciri-ciri antara lain: bersih, sehat, tidak keriput dan tidak ada luka bekas serangga. Dalam proses pemilihan benih, terlebih dahulu dilakukan perendaman benih cabai rawit (selama \pm 15 menit). Cara ini dimaksudkan agar kulit benih menjadi lunak dan mempercepat pertumbuhan benih. Benih yang terapung diambil dan disisihkan sedangkan benih yang terendam diambil dan digunakan sebagai benih yang akan ditanam.

\section{Penyemaian Benih Cabai Rawit}

Proses penyemaian benih cabai rawit dilakukan di bak semai yang telah berisi media tanah. Penyemaian benih dilakukan selama 10 hari sampai didapatkan daun sebanyak 2 helai dengan tinggi batang $10 \mathrm{~cm}$. 


\section{Persiapan Media Tanam}

Media tanam dibersihkan terlebih dahulu untuk menghilangkan kotoran yang tercampur dengan tanah. Disiapkan polibag $1 \mathrm{~kg}$, selanjutnya dicampurkan tanah $1 \mathrm{~kg}$ dengan pelet Trichoderma $\mathrm{sp}$ sesuai dengan perlakuan, kemudian didiamkan selama 1 minggu.

\section{Penanaman}

Proses penanaman dilakukan dengan cara mengambil bibit tanaman cabai rawit yang sudah tumbuh di bak semai, dimana bibit yang dipindahkan memiliki tinggi tanaman, jumlah daun, dan umur kriteria tanaman yaitu 10 hari dengan pertumbuhan seragam. Benih ditanam di polibag yang telah tersedia. Waktu penanaman dilakukan pada pagi hari untuk mengurangi terjadinya proses penguapan yang berlebihan.

\section{Pemeliharaan}

Kegiatan pemeliharaan meliputi penyiraman dan penyiangan gulma. Penyiraman dilakukan 2 kali sehari yaitu pada pagi dan sore hari, sedangkan penyiangan dilakukan dengan cara mencabut (membersihkan) rumput liar (gulma) dengan mencabut secara manual.

\section{Pengamatan}

Pengamatan dilakukan dengan interval 1 minggu sekali selama 1 bulan sejak pemindahan kedalam polibag.

\section{Analisis Data}

Data yang diperoleh dianalisis dengan menggunakan analisis sidik ragam. Jika perlakuan berpengaruh nyata, maka dilanjutkan dengan uji lanjut Beda Nyata Terkecil (BNT).

\section{HASIL DAN PEMBAHASAN}

Hasil analisis sidik ragam rata-rata tinggi tanaman cabai rawit (Capsicum frutescens L.) terhadap pemberian jamur Trichoderma sp didapatkan hasil Fhitung 5,97 > Ftabel 2,77 pada taraf 5\%. Hal ini menunjukkan bahwa pemberian Trichoderma sp pada berbagai konsentrasi perlakuan berpengaruh nyata terhadap pertumbuhan tinggi tanaman cabai rawit sehingga dilanjutkan dengan uji lanjut beda Nyata Terkecil (BNT).

Tabel 1. Hasil Uji BNT Rata-rata Tinggi Tanaman Cabai Rawit (Capsicum frutescens L.) Terhadap Pemberian Jamur Trichoderma sp.

\begin{tabular}{|c|c|}
\hline Perlakuan & $\begin{array}{c}\text { Rata-rata Tinggi Tanaman Cabai } \\
\text { Rawit }(\mathrm{cm})\end{array}$ \\
\hline P0 & $15,3 \quad \mathrm{a}$ \\
\hline $\mathrm{P} 1$ & $17,22 \mathrm{a}$ \\
\hline $\mathrm{P} 2$ & 17,32 a \\
\hline P3 & $25,7 \quad b$ \\
\hline $\mathrm{P} 4$ & $19,75 \quad b$ \\
\hline P5 & 18,92 a \\
\hline
\end{tabular}

BNT $^{(0,05)}: 4,37$

Ket: Rata-rata dalam tabel yang diikuti oleh huruf yang sama artinya tidak berbeda nyata pada uji BNT $5 \%$.

Pada Tabel 1 dapat dilihat bahwa pemberian Trichoderma sp terhadap pertumbuhan tinggi tanaman cabai rawit didapatkan rata-rata tinggi tanaman tertinggi dengan hasil tertinggi pada perlakuan P3 (75 g pelet Trichoderma sp/ $\mathrm{kg}$ tanah) yang menghasilkan rata-rata tinggi tanaman cabai $25,7 \mathrm{~cm}$, sedangkan hasil terendah pada perlakuan P0 (tanpa pelet Trichoderma sp) dengan rata-rata tinggi tanaman $15,3 \mathrm{~cm}$. 
Hasil analisis sidik ragam respons pertumbuhan diameter batang tanaman cabai rawit (Capsicum frutescens L.) didapatkan hasil Fhitung 55,35 > Ftabel 2,77 pada taraf $5 \%$. Hal ini menunjukkan bahwa pemberian Trichoderma sp pada berbagai konsentrasi perlakuan berpengaruh nyata terhadap diameter batang tanaman cabai rawit sehingga dilanjutkan dengan uji lanjut beda Nyata Terkecil (BNT).

Tabel 2. Hasil Uji BNT Rata-rata Diameter Batang Tanaman Cabai Rawit (Capsicum frutescens L.) Terhadap Pemberian Jamur Trichoderma sp.

\begin{tabular}{ccc}
\hline Perlakuan & $\begin{array}{c}\text { Rata-rata Diameter Batang } \\
\text { Tanaman Cabai Rawit }(\mathbf{m m})\end{array}$ \\
\hline P0 & 2,07 & $\mathrm{a}$ \\
P1 & 2,2 & $\mathrm{a}$ \\
P2 & 2,25 & $\mathrm{a}$ \\
P3 & 3,22 & $\mathrm{ab}$ \\
P4 & 2,72 & $\mathrm{a}$ \\
P5 & 2,62 & $\mathrm{a}$ \\
\hline
\end{tabular}

BNT $^{(0,05)}: 1,09$

Ket: Rata-rata dalam tabel yang diikuti oleh huruf yang sama artinya tidak berbeda nyata pada uji BNT 5\%.

Pada Tabel 2 menunjukkan bahwa respons pertumbuhan rata-rata diameter batang tanaman cabai rawit (Capsicum frutescens L.) terhadap pemberian jamur Trichoderma sp dengan hasil yang tertinggi didapat pada perlakuan P3 (75 g pelet Trichoderma $\mathrm{sp} / \mathrm{kg}$ tanah) dengan diameter batang rata-rata $3,22 \mathrm{~mm}$, sedangkan hasil terendah didapat pada pelakuan P0 (tanpa pelet Trichoderma sp) dengan diameter batang 2,07 $\mathrm{mm}$.
Hasil analisis sidik ragam ratarata jumlah daun tanaman cabai rawit (Capsicum frutescens L.) terhadap pemberian jamur Trichoderma $\mathrm{sp}$ didapatkan hasil Fhitung 3,84 > Ftabel 2,77 pada taraf $5 \%$. Hal ini menunjukkan bahwa pemberian jamur Trichoderma sp pada berbagai konsentrasi perlakuan berpengaruh nyata terhadap pertumbuhan tinggi tanaman cabai rawit sehingga dilanjutkan dengan uji lanjut Beda Nyata Terkecil (BNT).

Tabel 3. Hasil Uji BNT Respons Pertumbuhan Rata-rata Jumlah Daun Tanaman Cabai Rawit (Capsicum frutescens L.) Terhadap Pemberian Jamur Trichoderma sp.

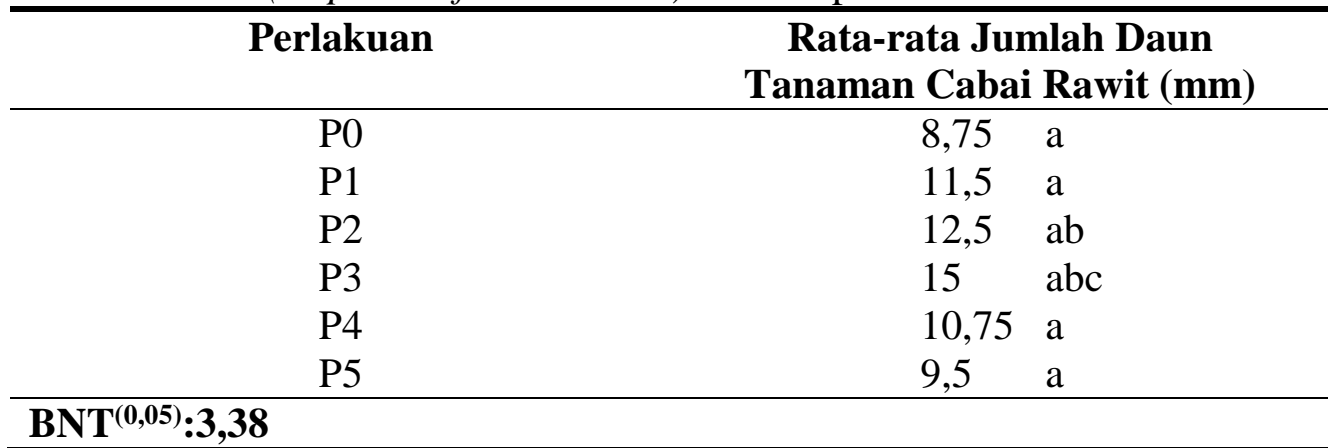

Ket: Rata-rata dalam tabel yang diikuti oleh huruf yang sama artinya tidak berbeda nyata pada uji BNT $5 \%$.

Pada Tabel 3 menunjukkan bahwa respons pertumbuhan rata-rata jumlah daun tanaman cabai rawit (Capsicum frutescens L.) terhadap pemberian jamur 
Trichoderma sp dengan hasil yang tertinggi didapat pada perlakuan P3 (75 g pelet Trichoderma $\mathrm{sp} / \mathrm{kg}$ tanah) yang menghasilkan rata-rata jumlah daun 15 helai, sedangkan hasil terendah terdapat pada pelakuan P0 (tanpa pelet Trichoderma sp) dengan rata-rata jumlah daun 8,75 helai.

Berdasarkan analisis sidik ragam didapatkan nilai Fhitung > Ftabel pada taraf 5\%. Hal ini menunjukkan bahwa pemberian Trichoderma sp pada berbagai konsentrasi perlakuan berpengaruh nyata terhadap pertumbuhan tinggi, diameter batang,dan jumlah daun tanaman cabai rawit. Penambahan Trichoderma sp pada konsentrasi tertentu dapat meningkatkan tinggi tanaman.

Pada Tabel 1 dapat dilihat bahwa hasil rata-rata tinggi tanaman pada perlakuan P0 (tanpa pemberian pelet Trichoderma sp) menghasilkan rata-rata tinggi tanaman 15,3 cm. Pada perlakuan P1 (25 g pelet Trichoderma $\mathrm{sp} / \mathrm{kg}$ tanah) menghasilkan tinggi $17,22 \mathrm{~cm}$. Pada perlakuan P2 (50 g pelet Trichodermma $\mathrm{sp} / \mathrm{kg}$ tanah) menghasilkan rata-rata tinggi tanaman 17,32 cm. Pada perlakuan P3 (75 $\mathrm{g}$ pelet Trichoderma $\mathrm{sp} / \mathrm{kg}$ tanah) menghasilkan rata-rata tinggi tanaman $25,7 \mathrm{~cm}$. Pada perlakuan P4 (100 g pelet Trichoderma $\mathrm{sp} / \mathrm{kg}$ tanah) menghasilkan rata-rata tinggi tanaman $19,75 \mathrm{~cm}$. Pada perlakuan P5 (125 g pelet Trichoderma sp/ $\mathrm{kg}$ tanah) menghasilkan rata-rata tinggi tanaman 18,92 cm. Perlakuan P0 tidak berbeda nyata dengan perlakuan P1,P2 dan P5, tetapi berbeda nyata pada perlakuan P3 dan P4. Sedangkan P3 dan $\mathrm{P} 4$ tidak berbeda nyata. Terjadi penurunan pertumbuhan tinggi tanaman yang diduga akibat koloni Trichoderma sp yang semakin banyak dan terjadi persaingan dalam mendapatkan nutrisi untuk pertumbuhannya sehingga pertumbuhan tanaman ikut terganggu. Pertumbahan tinggi tanaman merupakan bentuk peningkatan pembelahan sel-sel akibat adanya hasil asimilasi yang meningkat dan hasil asimilasi pada daun ini diangkut oleh pembuluh floem yang terdapat pada batang tanaman (Harjanti, et al.,2014). Hasil penelitian Septiani (2015) bahwa pemberian $25 \mathrm{~g}$ pelet Trichoderma $\mathrm{sp} / 2 \mathrm{~kg}$ tanah sudah mampu meningkatkan pertumbuhan tinggi tanaman dan jumlah daun pada tanaman tomat (Solanum lycopersicum). Trichoderma sp memberikan pengaruh positif terhadap perakaran tanaman, pertumbuhan tanaman dan hasil produksi tanaman. Penambahan Trichoderma sp akan meningkatkan efesiensi pemupukan. Pada tanah yang tandus pemberian Trichoderma sp memberikan hal yang maksimal pada tanaman. Trichoderma sp merupakaan mikroorganisme yang dikenal luas pada berbagai tanaman pertanian, dan bertindak sebagai biodekomposer. Trichoderma sp memberikan pengaruh positif terhadap perakaran tanaman, pertumbuhan tanaman dan hasil reproduksi tanaman. Sifat ini menandakan bahwa Trichoderma sp berperan dalam meningkatkan tanaman (Sastrahidayat, 2007).

Pada Tabel 2 dapat dilihat bahwa hasil rata-rata diameter batang tanaman cabai pada perlakuan P0 (tanpa pemberian pelet Trichoderma sp) menghasilkan ratarata diameter batang 2,07 $\mathrm{mm}$. Pada perlakuan P1 (25 g pelet Trichoderma sp/ $\mathrm{kg}$ tanah) menghasilkan rata-rata diameter batang 2,2 mm. Pada perlakuan P2 (50 g pelet Trichoderma $\mathrm{sp} / \mathrm{kg}$ tanah) menghasilkan rata-rata diameter batang 2,25 mm. Pada perlakuan P3 (75 g pelet Trichoderma $\mathrm{sp} / \mathrm{kg}$ tanah) menghasilkan rata-rata diameter batang 3,22 $\mathrm{mm}$. Pada perlakuan P4 (100 g pelet Trichoderma sp/ $\mathrm{kg}$ tanah) menghasilkan rata-rata diameter batang 2,72 mm. Pada perlakuan P5 (125 $\mathrm{g}$ pelet Trichoderma $\mathrm{sp} / \mathrm{kg}$ tanah) menghasilkan rata-rata diameter batang 2,62 mm. Pada perlakuan P0 tidak berbeda nyata dengan perlakuan $\mathrm{P} 1, \mathrm{P} 2$, P4 dan P5 tetapi berbeda nyata dengan 
perlakuan P3. Terjadinya penambahan diameter batang yang semakin lambat pertumbuhannya diduga kerena pertumbuhan koloni Trichoderma sp yang semakin banyak dan diikuti pelepasan zat dalam konsentrasi yang tinggi menyebabkan terganggunya pertumbuhan tanaman. Menurut Herlina (2009) bahwa senyawa asing yang dikeluarkan oleh tumbuhan ataupun organisme lain merupakan racun bagi tanaman karena senyawa tersebut dapat mengganggu proses metabolisme pada tanaman.

Pada Tabel 3 dapat dilihat bahwa hasil rata-rata jumlah daun tanaman cabai rawit pada perlakuan $\mathrm{P} 0$ (tanpa pemberian pelet Trichoderma sp) menghasilkan ratarata jumlah daun 8,75 helai. Pada perlakuan P1 (25 g pelet Trichoderma sp/ $\mathrm{kg}$ tanah) menghasilkan rata-rata jumlah daun 11,5 helai. Pada perlakuan P2 (50 g pelet Trichoderma $\mathrm{sp} / \mathrm{kg}$ tanah) menghasilkan rata-rata jumlah daun 11,25 helai. Pada perlakuan P3 (75 g pelet Trichoderma $\mathrm{sp} / \mathrm{kg}$ tanah) menghasilkan rata-rata jumlah daun 15 helai. Pada perlakuan P4 (100 g pelet Trichoderma sp/ $\mathrm{kg}$ tanah) menghasilkan rata-rata jumlah daun 10,75 helai. Pada perlakuan P5 (125 $\mathrm{g}$ pelet Trichoderma $\mathrm{sp} / \mathrm{kg}$ tanah) menghasilkan rata-rata jumlah daun 9,5 helai. Pada perlakuan P0 tidak berbeda nyata dengan perlakuan $\mathrm{P} 1, \mathrm{P} 4$ dan $\mathrm{P} 5$ tetapi berbeda nyata dengan perlakuan P2 dan P3. Trichoderma sp dapat meningkatkan pertumbuhan tanaman. Pemberian jamur Trichoderma sp pada berbagai konsentrasi perlakuan berpengaruh sangat nyata diduga karena jamur Trichoderma sp dapat berasosiasi dengan akar dan menginfeksi akar tanaman sehingga akar terbentuk cabang akar yang lebih banyak, dengan bantuan cabang akar tersebut maka proses penyerapan akan menjadi lancar dengan kebutuhan unsur hara yang cukup maka proses fotosintesis pada tanaman akan berlangsung dengan baik.
Penelitian Wahyu dan Pasetriyani (2006), menunjukkan bahwa introduksi 50/g jamur Trichoderma sp/polibag dapat mempertahankan pertumbuhan (tinggi tanaman dan jumlah daun) serta hasil (jumlah daun dan bobot buah) pada tanaman tomat. Pemberian Trichoderma sp dapat membantu merangsang jumlah daun tanaman tomat. Berdasarkan data di atas tinggi tanaman, diameter batang, dan jumlah daun tanaman cabai rawit cenderung meningkat seiring dengan meningkatnya pemberian konsentrasi Trichoderma sp sampai perlakuan $75 \mathrm{~g}$ pelet Trichoderma $\mathrm{sp} / \mathrm{kg}$ tanah tetapi setelah terjadi penambahan diatas $75 \mathrm{~g}$ pelet Trichoderma $\mathrm{sp} / \mathrm{kg}$ tanah terjadi penurunan.

Terjadi penurunan tinggi tanaman, diameter batang, dan jumlah daun diduga akibat koloni Trichoderma sp yang semakin banyak dan terjadi persaingan dalam mendapatkan nutrisi untuk pertumbuhannya sehingga pertumbuhan tanaman ikut terganggu. Menurut Novandini (2007) dalam Vancura dan Kunc (1988) Trichoderma sp mendapatkan nutrisi dari eksudat akar selain dari zat organik yang terikat pada tanah. Banyaknya zat yang dikeluarkan oleh akar tergantung dari jenis dan kondisi tanaman (Henry 2003). Eksudat yang dikonsumsi oleh Trichoderma sp untuk pertumbuhannya kemungkinan berupa asam organik ataupun hormon tumbuhan serta vitamin. Hasil buangan dari Trichoderma sp yang merupakan bentuk anorganik yang dapat dimanfaatkan kembali oleh tanaman. Hal ini sangat memudahkan tanaman serta Trichoderma sp dalam hal perolehan sumber nutrisi.

Pemberian jamur Trichoderma sp akan membantu pertumbuhan tanaman menjadi lebih baik. Berdasarkan hasil penelitian bahwa perlakuan yang berbedabeda menunjukkan hasil yang beragam pada pertumbuhan tanaman dengan menggunakan jamur Trichoderma $\mathrm{sp}$ 
dalam media bentuk pelet. Pelet merupakan salah satu media yang dapat digunakan untuk memperbanyak Trichoderma sp. Pelet mengandung karbohidrat, protein dan kandungan nutrisi sehingga Trichoderma sp dalam aplikasi seperti pelet dapat diberikan ke areal pertanaman dan berperan sebagai biodekomposer dan biofungisida (Lisa, 2009).

Hubungan timbal balik antara Trichoderma sp dengan tanaman adalah bersifat mutualisme. Tanaman diuntungkan dalam hal pertumbuhan maupun pengendalian penyakit, sedangkan Trichoderma sp diuntungkan karena mendapatkan nutrisi yang dihasilkan oleh tanaman. Trichoderma sp merupakan jamur tanah yang dapat diisolasi dari perakaran tanaman. Trichoderma sp diketahui sebagai pengendali hayati yang potensial pada beberapa patogen tanaman. Penggunaan Trichoderma sp sebagai agen hayati memiliki beberapa keunggulan yaitu: komperatif yang tinggi, mikroparasitik, mampu berkompetisi dalam memperoleh ruang, menghasilkan antibiotik dan enzim yang merugikan organisme patogen (Dina, 2003).

Menurut Maspary (2010), bahwa Trichoderma sp mempunyai kemampuan untuk meningkatkan kecepatan pertumbuhan dan perkembangan tanaman, terutama kemampuannya untuk menyebabkan produksi perakaran sehat dan meningkatkan angka kedalaman akar (lebih dalam dibawah permukaan tanah). Akar yang lebih dalam ini menyebabkan tanaman menjadi lebih resisten terhadap kekeringan. Tanaman Cabai Rawit berkecambah sampai muncul ke permukaan tanah membutuhkan waktu 35 hari setelah tanam. Masa vegetatif tanaman dimulai dari proses perkembangan biji semakin tinggi. Perkecambahan biji dapat terjadi apabila kandungan air di dalam biji semakin tinggi karena masuknya air kedalam biji melalui proses imbibisi (proses penyerapan air dan biji).

\section{KESIMPULAN}

Berdasarkan hasil penelitian yang telah dilakukan dapat diambil kesimpulan sebagai berikut: Perlakuan $75 \mathrm{~g}$ pelet Trichoderma $\mathrm{sp} / \mathrm{kg}$ tanah memberikan hasil tertinggi terhadap rata-rata tinggi tanaman yaitu $25,7 \mathrm{~cm}$, diameter batang $3,22 \mathrm{~mm}$, dan jumlah daun 15 helai, sedangkan hasil terendah pada perlakuan tanpa pelet Trichoderma sp dengan ratarata tinggi tanaman $15,3 \mathrm{~cm}$, diameter batang 2,07 mm, dan jumlah daun 8,75 helai.

\section{DAFTAR PUSTAKA}

Balai Proteksi Tanaman Perkebunan Palembang.2014. Jamur Trichoderma sp dalam Media Pelet. BPTP Palembang.

Dina. 2003. Pengendalian Hayati Patogen Tanaman Laporan Pelaksanaan Latihan Metodelogi Penelitian Pengendalian Hama dan Penyakit Tanaman. Kerjasama Badan Penelitian dan Pengembangan Hama dan Penyakit dan Jurusan Hama dan Penyakit Tumbuhan. IPB. Bandung.

Eddy, T. dan W.Y. Wahyu. 2006. Pengaruh Introduksi jamur Trichoderma sp terhadap Perkembangan Penyakit Layu Fusarium (Fusarium oxysporium). Pertumbuhan dan Hasil Tanaman Tomat. BPTP. Jawa Barat.

Herlina, L. 2009. Potensi Trichoderma harzianum sebagai Biofungisida pada Tanaman Tomat. Jurnal Biosainfitika. Vol.1 No.1. 
Maspary.2010. Cabai Rawit (Capsicum frustescens). (Http://www.Gerbang pertanian.com/2013/01/peranjamur-trichoderma-dalampertanian.html.). Diakses tanggal 24 Juli 2017.

Mukarlina, S. Khotimah dan R. Rianti. 2010. Uji Antagonis Trichoderma harzianum Terhadap Fusarium spp. Penyebab Penyakit Layu pada Tanaman Cabai (Capsicum annum) Secara In Vitro. Jurnal Fitomedika. 7(2): 80-85.

Novandini, A. 2007. Eksudat Akar Sebagai Nutrisi Trichoderma harzianum DT38 Serta Aplikasinya Terhadap Pertumbuhan Tanaman Tomat. Jurnal Institut Pertanian Bogor. Diakses tanggal 19 Agustus 2017.

Sastrahidayat, I.R. 2007. Ilmu Penyakit Tumbuhan. Usaha Nasional. Surabaya.

Septiani, M. 2015. Pengaruh Pemberian Trichoderma sp dalam meningkatkan Pertumbuhan Tanaman Tomat (Solanum lycopersicum). Skripsi . Universitas PGRI Palembang (Tidak dipublikasi).

Syukur, M., S. Sujiprihati, J. Koswara dan J. Widodo. 2009. Ketahanan Terhadap Antraknosa yang disebabkan oleh Colletotrichum acutatum pada Beberapa Genotif Cabai (Capsicum sp) dan Kolerasinya dengan Kandungan Kapsaicin dan Peroksidase. Jurnal Agronomi Indonesia. 37(3). 